\title{
Preventing Surgical Site Infections: A Clinical Perspective
}

\author{
Katherine $\mathrm{He}^{1,2}$, Allan Stolarski ${ }^{1,3}$, Edward Whang ${ }^{1,2}$, and Gentian Kristo ${ }^{1,2, *}$ \\ ${ }^{1}$ Department of Surgery, Veterans Affairs Boston Healthcare System, Boston, USA \\ ${ }^{2}$ Department of Surgery, Brigham and Women's Hospital, Harvard Medical School, Boston, USA \\ ${ }^{3}$ Department of Surgery, Boston Medical Center, Boston University, Boston, USA
}

*Corresponding author: Gentian Kristo, Department of Surgery, Veterans Affairs Boston Healthcare System (112-C), 1400 VFW Parkway, West Roxbury, Boston, MA 02132, USA, Tel: +1-857-2013-6966; Fax: +1-857-203-5738; E-mail: gentian.kristo@va.gov

Received: 22 Apr, 2020 | Accepted: 28 Apr, 2020 | Published: 01 May, 2020

Citation: He K, Stolarski A, Whang E, Kristo G (2020) Preventing Surgical Site Infections: A Clinical Perspective. J Surg Open Access 6(4): dx.doi.org/10.16966/2470-0991.217

Copyright: (c) $2020 \mathrm{He} \mathrm{K}$, et al. This is an open-access article distributed under the terms of the Creative Commons Attribution License, which permits unrestricted use, distribution, and reproduction in any medium, provided the original author and source are credited.

\begin{abstract}
Surgical Site Infections (SSIs) are associated with increased morbidity and higher healthcare costs. Given that most SSIs are considered preventable when using evidence-based strategies, SSI has become an important subject of quality improvement studies as well as a metric for surgeon compensation.

Various organizations have issued guidelines for the prevention of SSIs that address patient-specific risk factors, and interventions aimed at the prehospital, hospital, and post-discharge stages of care.

In this review, we reconcile the SSI prevention guidelines from three organizations: Centers for Disease Control and Prevention, World Health Organization, and the American College of Surgeons/Surgical Infection Society.

These guidelines agree on the majority of preventative measures. Each guideline also addresses additional measures based on the grade of the evidence established for the guideline as well as the target audiences and priorities for each organization.

Guidelines for SSI prevention are important, but their success depends on sound implementation and compliance. Sustained efforts from all healthcare providers and organizational leaders are crucial to prevent SSIs.
\end{abstract}

Keywords: Surgical site infection; Prevention; guidelines; Quality improvement; Implementation

\section{Introduction}

Surgical Site Infections (SSIs) are the most common healthcareassociated infections among surgical patients [1] and are associated with substantial morbidity.

SSIs are associated with approximately 8,205 deaths each year in the US, and account for an estimated $11 \%$ of all deaths in intensive care units [2]. They increase the hospital stay by 11 days per patient [3] and are the most frequent cause (20\%) of unplanned readmissions after surgery [4]. The financial burden of SSIs is significant, with overall US cost estimates of $\$ 3.5$-10 billion annually, approximately $\$ 12,000$ to $\$ 35,000$ per patient [5]. Because about $60 \%$ of SSIs are considered preventable [6], SSI has become an important metric for quality improvement and pay-for-performance.

To standardize SSI data collection, the Centers for Disease Control and Prevention (CDC) has defined SSI based on depth and tissue space involved [7] (Figure 1). In the criteria put forth by the CDC, SSIs are classified as either incisional or organ/space, with incisional SSIs being further subclassified as superficial (involving only skin and subcutaneous tissue) versus deep (involving underlying fascia and muscle).
Table 1 describes the criteria used by the CDC to classify SSI into its various categories [8]. These criteria are used for surveillance purposes, and allow for objective definitions in quality improvement, public reporting, pay-for-performance and research.

In this paper we aim to provide a contemporary review of the SSI prevention guidelines from three organizations: Centers for Disease Control and Prevention, World Health Organization, and the American College of Surgeons/Surgical Infection Society.

\section{Methods}

A diverse team of authors, including general surgery residents and attending surgeons, conducted a narrative review of the literature on prevention of surgical site infections. We conducted a non-systematic search for peer-reviewed, English language studies published between 2000 and 2019. Reference lists of articles were reviewed to identify additional studies. The entire team of authors identified key findings in the literature related to surgical site infections, and the final results are the key points presented in this review. According to the VA Boston Healthcare System policy, our study was exempt from Institutional Board Review. 


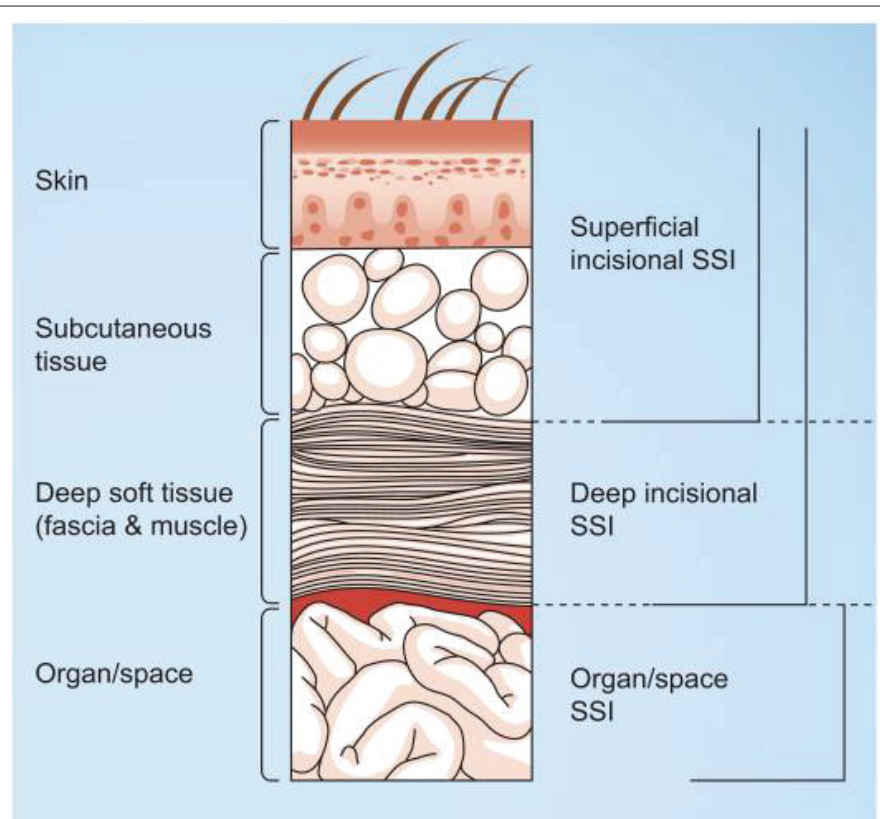

Figure 1: Classification of surgical site infections according to CDC National Nosocomial Surveillance System (adapted from Horan TC, et al. [7]).

\section{Results and Discussion}

\section{Microbiology of SSI's}

Overall, the most commonly involved organisms are part of the patient's endogenous flora, such as Staphylococcus aureus, coagulasenegative staphylococci, Enterococcus spp., and Escherichia coli [8]. In clean surgical procedures (in which the gastrointestinal, gynecologic, and respiratory tracts have not been entered), endogenous Staphylococcus aureus from the patient's skin flora is the most common cause of infection. In contaminated surgical procedures (in which there is entry into hollow viscera) gram-negative bacilli such as Escherichia coli, gram-positive organisms such as Enterococcus spp., anaerobes such as Bacillus fragilis, and, occasionally, yeast species [8] are usually encountered.

SSI's may also be caused by aerobic microorganisms (such as staphylococci and streptococci) colonizing surgical personnel, operating room environment, and surgical instruments or materials used during operations.

Resistant pathogens are increasingly involved in the development of SSI's. In particular, there has been a noted rise in SSIs due to Methicillin-Resistant S. aureus (MRSA), Vancomycin-Resistant Enterococci (VRE), third-generation cephalosporin-resistant Escherichia coli, and imipenem- and quinolone-resistant Pseudomonas aeruginosa. Resistance to antimicrobial therapy has been associated with prolonged duration of treatment and hospital stays, higher costs, and increased mortality [9]. For adequate antimicrobial stewardship, antibiotic prophylaxis for surgical interventions should consider the expected flora, bacterial resistance patterns, drug pharmacokinetics, and duration of 24 hours or less.

Table 2 further expands upon the most likely pathogens encountered in different surgical procedures.

\section{Risk factors}

There are several modifiable and non-modifiable (intrinsic) patient risk factors for SSIs. C Some modifiable risk factors include diabetes, obesity, dyspnea, alcoholism, smoking, preoperative albumin $<3.5 \mathrm{mg}$ / $\mathrm{dL}$, total bilirubin $>1.0 \mathrm{mg} / \mathrm{dL}$, and immunosuppression [10]. Nonmodifiable (intrinsic) patient factors include advanced age, recent chemotherapy and radiation treatment for cancer, and pre-existing skin or soft tissue infections.

Extrinsic risk factors include emergency and more complex surgeries; higher wound classification; inadequate Operating Room (OR) ventilation; increased OR traffic; improper sterilization of surgical instruments; inadequate skin preparation; hair removal and method; improper prophylactic antibiotic choice, administration, and duration; prolonged duration of surgery, intraoperative blood transfusion; improper surgical hand scrubbing and gloving; and intraoperative hypothermia and poor glycemic control $[8,10]$. Table 3 further expands upon the risk factors for developing SSI.

\section{Guidelines for prevention}

Various organizations have developed their specific guidelines for the prevention of SSI. In 1999, the CDC released expert opinion for the prevention of SSIs [8]. The World Health Organization (WHO) published SSI prevention guidelines in 2016 [11] and the American College of Surgeons and the Surgical Infection Society (ACS/SIS) published their guidelines in 2017 [10]. The CDC subsequently updated its SSI prevention guidelines in 2017, based on a contemporary literature review [12].

These guidelines are concordant on the majority of preventative measures. Each guideline also addresses additional measures based on the level and quality of evidence established for the guideline as well as the target audiences and priorities for each organization. Their summarized recommendations are discussed in detail below.

\section{Prehospital interventions}

Prehospital interventions for reducing SSI include preoperative bathing, smoking cessation, glucose control, MRSA screening, and bowel preparation (Table 4).

Preoperative bathing: Preoperative bathing with chlorhexidine 
Table 1: CDC Surgical Site Infection (SSI) Classification (adapted from Mangram AJ, et al. [8]).

\section{Superficial Incisional SSI}

Infection occurs within 30 days after the operation and infection involves only skin or subcutaneous tissue of the incision and at least one of the following:

1. Purulent drainage, with or without laboratory confirmation, from the superficial incision.

2. Organisms isolated from an aseptically obtained culture of fluid or tissue from the superficial incision.

3. At least one of the following indicators of infection: pain or tenderness, localized swelling, redness, or heat and superficial incision is deliberately opened by surgeon, unless incision is culture-negative.

4. Diagnosis of superficial incisional SSI by the surgeon or attending physician.

Do not report the following conditions as SSI

1. Stitch abscess (minimal inflammation and discharge confined to the points of suture penetration).

2. Infection of an episiotomy or newborn circumcision site.

3. Infected burn wound.

4. Incisional SSI that extends into the facial and muscle layers (see deep incisional SSI).

Note: Specific criteria are used for identifying infected episiotomy and circumcision sites and burn wounds.

\section{Deep incisional SSI}

Infection occurs within 30 days after the operation if no prosthetic implant is left in place or within 1 year if implant is in place and the infection appears to be related to the operation and infection involves deep soft tissues (e.g., facial and muscle layers) of the incision and at least one of the following:

1. Purulent drainage from the deep incision but not from the organ/space component of the surgical site.

2. A deep incision spontaneously dehisces or is deliberately opened by a surgeon when the patient has at least one of the following signs or symptoms: fever $\left(>38^{\circ} \mathrm{C}\right)$, localized pain, or tenderness, unless site is culture-negative.

3. An abscess or other evidence of infection involving the deep incision is found on direct examination, during reoperation, or by histopathologic or radiologic examination.

4. Diagnosis of a deep incisional SSI by a surgeon or attending physician.

Notes:

1. Report infection that involves both superficial and deep incision sites as deep incisional SSI.

2. Report an organ/space SSI that drains through the incision as a deep incisional SSI.

\section{Organ/space SSI}

Infection occurs within 30 days after the operation if no prosthetic implant is left in place or within 1 year if implant is in place and the infection appears to be related to the operation and infection involves any part of the anatomy (e.g., organs or spaces), other than the incision, which was opened or manipulated during an operation and at least one of the following:

1. Purulent drainage from a drain that is placed through a stab wound into the organ/space.

2. Organisms isolated from an aseptically obtained culture of fluid or tissue in the organ/space.

3. An abscess or other evidence of infection involving the organ/space that is found on direct examination, during reoperation, or by histopathologic or radiologic examination.

4. Diagnosis of an organ/space SSI by a surgeon or attending physician.

ҒIf the area around a stab wound becomes infected, it is not an SSI. It is considered a skin or soft tissue infection, depending on its depth.

reduces the concentration of skin surface microorganisms, but has not been shown to reduce the SSI risk [10].

Smoking cessation: Smoking cessation 4 to 6 weeks preoperatively is shown to reduce SSI $[10,12]$, and is recommended for all current smokers. Nicotine-containing substances (e.g. gum, patch, and lozenges) are not shown to increase SSI risk [10]. Cessation of marijuana and electronic cigarette use has not proven to prevent SSI.

Glucose control: Normoglycemia is recommended for all diabetic patients; however, improved Hgb A1C levels have not resulted in reduced SSI risk [10].
MRSA screening: MRSA colonization increases the risk and severity for both MRSA SSI and SSI overall [13-15]. MRSA bundles include screening, pre-operative decolonization, contact precautions, hand hygiene, and vancomycin-containing antibiotic prophylaxis.

Preoperative decolonization protocols usually include the use of nasal mupirocin alone vs. nasal mupirocin plus chlorhexidine gluconate bathing, although no standard decolonization protocol is supported by literature [10].

For antibiotic prophylaxis, use of vancomycin alone in MRSAnegative patients is associated with a higher risk of methicillin- 
Table 2: Pathogens commonly associated with different surgical procedures (adapted from Mangram AJ, et al. [8]).

\begin{tabular}{|c|c|}
\hline Type of Surgery & Common pathogens \\
\hline $\begin{array}{l}\text { Placement of all grafts, prostheses, or } \\
\text { implants }\end{array}$ & S aureus; coagulase-negative staphylococci \\
\hline Cardiac & S aureus; coagulase-negative staphylococci \\
\hline Thoracic & S aureus; coagulase-negative staphylococci, Streptococcus pneumoniae, gram-negative bacilli \\
\hline Breast & S aureus; coagulase-negative staphylococci \\
\hline Ophthalmic & S aureus; coagulase-negative staphylococci; streptococci; gram-negative bacilli \\
\hline Orthopedic & S aureus; coagulase-negative staphylococci; streptococci; gram-negative bacilli \\
\hline Vascular & S aureus; coagulase-negative staphylococci \\
\hline Appendectomy & Gram-negative bacilli; anaerobes \\
\hline Biliary tract & Gram-negative bacilli; anaerobes \\
\hline Colorectal & Gram-negative bacilli; anaerobes \\
\hline Gastroduodenal & Gram-negative bacilli; streptococci; oropharyngeal anaerobes (e.g. peptostreptococci) \\
\hline Head and neck & S. aureus; streptococci; oropharyngeal anaerobes (e.g. peptostreptococci) \\
\hline Obstetric and gynecological & Gram-negative bacilli; enterococci; Group B streptococci; anaerobes \\
\hline Urological & Gram-negative bacilli \\
\hline
\end{tabular}

Table 3: Risk factors for surgical site infections (adapted from Ban KA, et al. [10]).

\begin{tabular}{|c|c|c|c|c|c|}
\hline \multicolumn{2}{|c|}{ Intrinsic (patient) risk factors } & \multicolumn{4}{|c|}{ Extrinsic (procedural) risk factors } \\
\hline Modifiable & Non-modifiable & Procedure & Facility & Pre-operative & Intra-operative \\
\hline $\begin{array}{l}\text { Diabetes } \\
\text { Obesity } \\
\text { Alcoholism } \\
\text { Current smoker } \\
\text { Preoperative albumin }<3.5 \\
\mathrm{mg} / \mathrm{dL} \\
\text { Total bilirubin }>1.0 \mathrm{mg} / \mathrm{dL} \\
\text { Immunosuppression }\end{array}$ & $\begin{array}{l}\text { Increased age } \\
\text { Recent radiotherapy } \\
\text { History of skin or soft } \\
\text { tissue infection }\end{array}$ & $\begin{array}{l}\text { Emergency } \\
\text { Increasing } \\
\text { complexity } \\
\text { Higher wound } \\
\text { classification }\end{array}$ & $\begin{array}{l}\text { Inadequate } \\
\text { ventilation } \\
\text { Increased operating } \\
\text { room traffic } \\
\text { Contaminated } \\
\text { environmental } \\
\text { surfaces } \\
\text { Non-sterile } \\
\text { equipment }\end{array}$ & $\begin{array}{l}\text { Pre-existing infection } \\
\text { Inadequate skin } \\
\text { preparation } \\
\text { Inappropriate antibiotic } \\
\text { choice, timing, and } \\
\text { weight-based dosing } \\
\text { Hair removal method } \\
\text { Poor glycemic control }\end{array}$ & $\begin{array}{l}\text { Longer procedure } \\
\text { duration } \\
\text { Blood transfusion } \\
\text { Breach in asepsis } \\
\text { Inappropriate antibiotic } \\
\text { re-dosing } \\
\text { Inadequate gloving } \\
\text { Inappropriate surgical } \\
\text { scrub } \\
\text { Poor glycemic control }\end{array}$ \\
\hline
\end{tabular}

Table 4: Guidelines for prehospital interventions as endorsed by specific guidelines. (adapted from Ban KA, et al. [10], Allegranzi B, et al. [11], and Berrios-Torres $\mathrm{SI}$, et al. [12]).

\begin{tabular}{|l|l|}
\hline \multicolumn{1}{|c|}{ Guideline (Organization) } & \multicolumn{1}{c|}{ Recommendation } \\
\hline $\begin{array}{l}\text { Preoperative bathing } \\
\text { (CDC; ACS/SIS) }\end{array}$ & $\begin{array}{l}\text { Routine preoperative bathing with chlorhexidine reduces the bacterial colonization of the skin, but has not } \\
\text { been shown to reduce SSI. }\end{array}$ \\
\hline $\begin{array}{l}\text { Smoking cessation } \\
\text { (CDC; ACS/SIS) }\end{array}$ & $\begin{array}{l}\text { Smoking cessation } 4 \text { to } 6 \text { weeks before surgery reduces SSI and is recommended for all current smokers, } \\
\text { especially those undergoing procedures with implanted materials. There is no literature to support cessation } \\
\text { of marijuana and electronic cigarette use to prevent SSI. }\end{array}$ \\
\hline $\begin{array}{l}\text { Glucose control } \\
\text { (CDC; ACS/SIS; WHO) }\end{array}$ & $\begin{array}{l}\text { Optimal blood glucose control should be encouraged for all diabetic patients; however, there is no evidence } \\
\text { that improved Hgb A1C decreases SSI risk. }\end{array}$ \\
\hline MRSA screening & $\begin{array}{l}\text { MRSA bundles (screening, decolonization, contact precautions, hand hygiene) are highly effective if adhered } \\
\text { to, otherwise there is no benefit. } \\
\text { (ACS/SIS; WHO) }\end{array}$ \\
$\begin{array}{l}\text { No standard decolonization protocol supported by literature; consider nasal mupirocin alone vs. nasal } \\
\text { mupirocin plus chlorhexidine gluconate bathing. } \\
\text { Decolonization protocols should be completed close to date of surgery to be effective. } \\
\text { Vancomycin should not be administered as prophylaxis to MRSA-negative patients. }\end{array}$ \\
\hline $\begin{array}{l}\text { Bowel preparation } \\
\text { (ACS/SIS) }\end{array}$ & Combination mechanical and antibiotic oral preparation is recommended for all elective colectomies. \\
\hline
\end{tabular}

CDC-Centers for Disease Control and Prevention

ACS/SIS-American College of Surgeons and the Surgical Infection Society

WHO-World Health Organization 
sensitive $S$ aureus SSI [16] and an increased risk of conversion to MRSA-positive status and development of SSI [17]. As such, routine administration of vancomycin-only antibiotic prophylaxis in MRSAnegative patients is not recommended [10].

Bowel preparation: Mechanical bowel preparation alone or oral antibiotics alone are not shown to decrease SSIs [18-20]. The combination of mechanical and oral antibiotic bowel preparation is recommended for all elective colorectal surgeries as they reduce the risk of SSI, anastomotic leak, Clostridium difficile infection, postoperative ileus, prolonged hospitalization, and readmissions [18-21,22,23]. Routine intravenous prophylactic antibiotics in the immediate preoperative period should also be given.

\section{Hospital interventions}

Hospital interventions for reducing SSI include perioperative glucose control; hair removal; preoperative skin preparation; surgical hand scrub; surgical attire; prophylactic antibiotics; maintaining normothermia; maintaining normovolemia; wound protectors; antibiotic sutures; gloves/instruments; adhesive incise drapes; incisional wound irrigation; operating room ventilation; and wound care (Table 5).

Perioperative glucose control: Perioperative hyperglycemia is associated with increased SSI's in both diabetic and nondiabetic patients [24-26]. As such, implementation of perioperative glycemic control protocols is strongly recommended [10-12], with blood glucose target levels less than $200 \mathrm{mg} / \mathrm{dL}$ in all patients. There is no evidence to recommend specific hemoglobin A1C target levels for SSI prevention. Furthermore, short-term glucose control has been shown to be more beneficial than the long-term control of hemoglobin A1C for SSI prevention [10].

Close monitoring of blood glucose levels is very important as hypoglycemia can occur with peri-operative glycemic control protocols.

Hair removal: Hair removal should be avoided unless hair interferes with the surgical intervention. If hair removal is deemed necessary, it is recommended to use clippers instead of a razor $[10,12]$.

Preoperative skin preparation: The use of alcohol-based skin scrubs is strongly recommended and has been shown to be more effective in reducing SSI than aqueous preparations [10,12]. When comparing chlorhexidine- to iodine-based alcohol solutions, there is no clear superior agent to reduce SSI $[10,12]$. In the absence of alcohol, chlorhexidine gluconate may be superior to povidone-iodine.

Surgical hand scrub: Use of a chlorhexidine scrub is as effective as traditional water scrub and requires less time $[10,12]$. Water based scrub for a first case is recommended. Hand hygiene with soap and water is also recommended prior to waterless scrub for subsequent cases.

Surgical attire: In the operating room, a proper surgical mask should fully cover the mouth and nose. All scalp and facial hair should be properly covered $[10,12]$. Skull caps are now accepted in addition to the bouffant cap.

Head and neck jewelry be removed. Operating room scrubs should be removed or properly covered when leaving the operating room areas [10].

Prophylactic antibiotics: Prophylactic antibiotics are strongly recommended with the antibiotic choice being guided dictated by considerations such as the type of the surgical procedure and the most likely infecting pathogens. To achieve bactericidal concentration at time of the surgical incision, administration of weight-adjusted antibiotics should be completed within 1 hour prior to making an incision (2 hours for vancomycin or fluoroquinolones) [10-12]. To maintain adequate tissue levels, antibiotics should be redosed based on agent half-life or for every 1,500 mL blood loss [10].

Administration of prophylactic antibiotic after closure of the incision in clean and clean-contaminated surgeries is not shown to prevent SSI, even in the presence of a drain (exceptions include implant-based breast reconstruction, joint arthroplasty, and cardiac procedures) [10-12].

Although there is no evidence to recommend an optimal time for removal of wound drains, they should be removed as soon as clinically indicated [10-12].

Perioperative supplemental oxygenation: Adequate tissue oxygenation at the site of the incision is considered beneficial in preventing SSIs. Infected tissue has a lower oxygentension than noninfected tissue [27]. Administration of high-concentration oxygen $\left(80 \% \mathrm{FiO}_{2}\right)$ provides enhanced incisional oxygenation, and has the potential to augment oxidative killing by neutrophils [28].

Intubated adult patients with normal pulmonary function should receive $80 \%$ fraction of inspired oxygen during the surgery [1012] and for 2-6 hours post-operatively if feasible [10,11]. There is no recommended optimal oxygen delivery method or a target oxygenation level.

Maintaining normothermia: Given evidence that perioperative hypothermia (core temperature $<36^{\circ} \mathrm{C}$ ) increases the risk of SSI [29], maintenance of normothermia is strongly recommended [1012]. However, there is no sufficient evidence to recommend optimal strategies to achieve and maintain normothermia.

Maintaining normovolemia: Fluid imbalance (hypovolemia and hypervolemia) can affect tissue perfusion leading to decreased tissue oxygenation and a subsequent increase the risk of SSI [30]. As such, intraoperative goal-directed fluid therapy is suggested for preventing SSI [11]. There is no evidence to suggest the optimal type of fluid to be administered.

Wound protectors: Impermeable plastic wound protectors are shown to be beneficial in preventing SSI in open abdominal surgery, especially in colorectal and biliary tract procedures [10,11].

Antibiotic sutures: Triclosan antibiotic sutures are shown to reduce the risk of SSI [31], and as such they are recommended for wound closure in any type of surgery [10-12].

Gloves/Instruments: Because double gloving is shown to reduce the risk of holes to the inner glove, it is recommended for protecting the surgeon and reduce surgical cross-contamination [32].

Despite lack of supporting evidence, changing gloves before closure and the use of new instruments is recommended in colorectal surgery based on expert consensus [33]. Rescrubbing before closure in colorectal cases is not recommended [10].

Adhesive drapes: the uses of plastic adhesive incise drapes with or without antimicrobial properties is not recommended for reducing the SSI risk [10-12]. There is no evidence to support the use of microbial sealants after adequate intraoperative skin preparation.

Incisional wound irrigation: Incisional wound irrigation with an aqueous povidone-iodine solution before closure can be considered as it might reduce SSI, especially in clean and clean-contaminated 
Table 5: Guidelines for hospital interventions. (adapted from Ban KA, et al. [10], Allegranzi B, et al. [11], and Berrios-Torres SI, et al. [12]).

\begin{tabular}{|c|c|}
\hline $\begin{array}{l}\text { Guideline } \\
\text { (Organization) }\end{array}$ & Recommendation \\
\hline $\begin{array}{l}\text { Perioperative glucose } \\
\text { control } \\
\text { (CDC; ACS/SIS; WHO) }\end{array}$ & $\begin{array}{l}\text { Perioperative hyperglycemia increases the risk of SSI in both diabetics and nondiabetics. As such, implementation of } \\
\text { perioperative glycemic control protocols is strongly recommended, with blood glucose target levels less than } 200 \mathrm{mg} / \mathrm{dL} \text { in } \\
\text { patients with and without diabetes. } \\
\text { There is no evidence to recommend an optimal hemoglobin A1C target levels for the prevention of SSI. }\end{array}$ \\
\hline $\begin{array}{l}\text { Hair removal } \\
\text { (CDC; ACS/SIS) }\end{array}$ & $\begin{array}{l}\text { Hair removal should be avoided unless hair interferes with surgery. If hair removal is necessary, clippers should be used } \\
\text { instead of a razor. }\end{array}$ \\
\hline $\begin{array}{l}\text { Preoperative skin } \\
\text { preparation } \\
\text { (CDC; ACS/SIS) }\end{array}$ & $\begin{array}{l}\text { The use of prophylactic antibiotics is strongly recommended with the choice of prophylactic } \\
\text { Alcohol-containing preparations are more effective in reducing SSI than aqueous preparations and should be used unless } \\
\text { contraindications exist. When comparing chlorhexidine- to iodine-based alcohol solutions, there is no clear superior agent } \\
\text { to reduce SSI. In the absence of alcohol, chlorhexidine gluconate may be superior to povidone-iodine. }\end{array}$ \\
\hline $\begin{array}{l}\text { Surgical hand scrub } \\
\text { (CDC; ACS/SIS) }\end{array}$ & $\begin{array}{l}\text { Use of a waterless chlorhexidine scrub is as effective as traditional water scrub and requires less time, but there is no } \\
\text { superior agent if used according to manufacturer instructions. }\end{array}$ \\
\hline $\begin{array}{l}\text { Surgical attire } \\
\text { (CDC; ACS/SIS) }\end{array}$ & $\begin{array}{l}\text { In the operating room wear a surgical mask that fully covers the mouth and nose, and use a skull cap if minimal hair is } \\
\text { exposed. } \\
\text { Remove or cover all jewelry on the head and neck, and professional attire when outside the operating room (no scrubs or } \\
\text { clean scrubs covered with a white coat). }\end{array}$ \\
\hline $\begin{array}{l}\text { Prophylactic antibiotics } \\
\text { (CDC; ACS/SIS; WHO) }\end{array}$ & $\begin{array}{l}\text { The use of prophylactic antibiotics is strongly recommended with the choice of prophylactic antibiotic dictated by the type } \\
\text { of the surgical procedure and pathogens most likely to cause SSI. } \\
\text { Administration of antibiotics should be completed within } 1 \text { hour prior to incision ( } 2 \text { hrs for vancomycin or fluoroquinolone). } \\
\text { Antibiotics should be redosed based on agent half-life or for every } 1,500 \mathrm{~mL} \text { blood loss. } \\
\text { There is no evidence that prophylactic antibiotic administration after incision closure decreases SSI risk. } \\
\text { The presence of a wound drain does not require prophylactic antibiotic. }\end{array}$ \\
\hline $\begin{array}{l}\text { Perioperative } \\
\text { oxygenation } \\
\text { (CDC; ACS/SIS; WHO) }\end{array}$ & $\begin{array}{l}\text { Adult patients with normal pulmonary function undergoing general anesthesia with endotracheal intubation for surgical } \\
\text { procedures should receive } 80 \% \text { fraction of inspired oxygen intraoperatively and, if feasible, in the immediate postoperative } \\
\text { period for } 2-6 \mathrm{~h} \text {. There is no evidence to recommend an optimal oxygen delivery method or a target oxygenation level. }\end{array}$ \\
\hline $\begin{array}{l}\text { Maintaining } \\
\text { normothermia } \\
\text { (CDC; ACS/SIS; WHO) }\end{array}$ & $\begin{array}{l}\text { Perioperative maintenance of normothermia is strongly recommended. There is no evidence to recommend optimal } \\
\text { strategies to achieve and maintain normothermia, the lower limit of normothermia, or the optimal timing and duration of } \\
\text { normothermia for the prevention of SSI. }\end{array}$ \\
\hline $\begin{array}{l}\text { Maintaining } \\
\text { normovolemia } \\
\text { (WHO) }\end{array}$ & Intraoperative goal-directed fluid therapy is suggested for preventing SSI. \\
\hline $\begin{array}{l}\text { Wound protectors } \\
\text { (ACS/SIS; WHO) }\end{array}$ & $\begin{array}{l}\text { Use of an impervious plastic wound protector can prevent SSI in open abdominal surgery. Evidence is strongest for elective } \\
\text { colorectal and biliary tract procedures. }\end{array}$ \\
\hline $\begin{array}{l}\text { Antibiotic sutures } \\
\text { (CDC; ACS/SIS; WHO) }\end{array}$ & Triclosan antibacterial suture use is recommended for wound closure in any type of surgery when available. \\
\hline $\begin{array}{l}\text { Gloves / Instruments } \\
\text { (ACS/SIS) }\end{array}$ & $\begin{array}{l}\text { The use of double gloves is recommended. } \\
\text { Changing gloves before closure in colorectal cases is recommended, however, rescrubbing before closure in colorectal cases } \\
\text { is not recommended. } \\
\text { The use of new instruments for closure in colorectal cases is recommended. }\end{array}$ \\
\hline $\begin{array}{l}\text { Adhesive drapes } \\
\text { (CDC; ACS/SIS; WHO) }\end{array}$ & $\begin{array}{l}\text { Plastic adhesive incise drapes with or without antimicrobial properties are not necessary for the prevention of the SSI and } \\
\text { should not be used. Application of microbial sealant immediately after skin preparation is not needed. }\end{array}$ \\
\hline $\begin{array}{l}\text { Incisional wound } \\
\text { irrigation (CDC; WHO) }\end{array}$ & $\begin{array}{l}\text { Consider the use of irrigation of the incisional wound with an aqueous povidone-iodine solution before closure, particularly } \\
\text { in clean and clean-contaminated wounds. } \\
\text { Intraperitoneal lavage with aqueous iodophor solution in contaminated or dirty abdominal procedures is not necessary. } \\
\text { Antibiotic incisional wound irrigation before closure should not be used. }\end{array}$ \\
\hline $\begin{array}{l}\text { Operating room } \\
\text { ventilation (CDC; WHO) }\end{array}$ & $\begin{array}{l}\text { Maintain positive pressure ventilation in the operating room and adjoining spaces. } \\
\text { Laminar airflow ventilation systems should not be used for patients undergoing total arthroplasty surgery. }\end{array}$ \\
\hline $\begin{array}{l}\text { Wound care } \\
\text { (CDC; ACS/SIS; WHO) }\end{array}$ & $\begin{array}{l}\text { No type of advanced dressing should be used over a standard dressing on primarily closed surgical wounds. } \\
\text { Use of wound vacuum therapy over stapled skin can reduce SSI in open colorectal (abdominal incision) and vascular (groin } \\
\text { incision) cases. } \\
\text { Mupirocin topic antibiotic application can decrease SSI compared with a standard dressing. } \\
\text { While close incisions are usually covered with a sterile dressing for } 24-48 \text { hrs postoperatively, there is no evidence in the } \\
\text { literature that timing of dressing removal increases SSI risk. } \\
\text { Early showering ( } 12 \text { hours postoperative) does not increase the risk of SSI. } \\
\text { Daily wound probing can decrease SSI in contaminated wounds. }\end{array}$ \\
\hline
\end{tabular}

CDC-Centers for Disease Control and Prevention; ACS/SIS-American College of Surgeons and the Surgical Infection Society; WHO-World Health Organization 
procedures $[11,12]$. There is no evidence to support the antibacterial irrigation of the peritoneal cavity in contaminated or dirty abdominal surgeries [12]. Antibacterial irrigation of the wound before closure is discouraged because it has no proven benefits and could lead to antimicrobial resistance [11].

Operating room ventilation: The air pressure in operating room should be higher than in adjacent areas [12] to prevent air flowing from these less sterile areas into the operating room [34]. Laminar (unidirectional) airflow ventilation systems have shown no benefits in reducing SSI event during total arthroplasty procedures [11].

Wound care: Given lack of benefits of advanced dressings, only a standard dressing is recommended for primarily closed incisions [10]. Use of negative pressure therapy over stapled skin closure has been shown to reduce the risk of infection of abdominal incisions after colorectal surgery, and groin incisions after and vascular procedures $[10,11]$.

It has been common practice to protect closed incisions with a sterile dressing for $24-48$ hours after surgery $[8,12]$ in order to protect the wound from micro-organisms and subsequent infection. However, the timing of dressing removal has not been shown to play a role in SSI's. Furthermore, there is no evidence that early showering (less than 12 hours after surgery) increases the SSI risk [10].

Daily probing of closed wounds until cessation of drainage can decrease SSI after contaminated surgeries [10].

\section{Post-hospital interventions}

Adequate SSI surveillance after discharge is very important because a significant number of SSIs develop after patients leave the hospital. However, currently there is insufficient research exploring posthospital discharge interventions to prevent SSI.

\section{Conclusion}

Sustained efforts from all healthcare providers and organizational leaders are crucial for preventing SSIs. Guidelines for SSI prevention are important, but their success depends on sound implementation and compliance. Structuring available guidelines in simple bundles of care by multidisciplinary teams based on institution characteristics and resources, has been shown to improve standardization, automation, and education of staff and patients, ultimately decreasing the rate of SSI.

\section{References}

1. Weigelt JA, Lipsky BA, Tabak YP, Derby KG, Kim M, et al. (2010) Surgical site infections: causative pathogens and associated outcomes. Am J Infect Control 38: 112-120.

2. Klevens RM, Edwards JR, Richards CL Jr, Horan TC, Gaynes RP, et al. (2007) Estimating healthcare-associated infections and deaths in U.S. Hospitals, 2002. Public Health Reports 122: 160-166.

3. Zimlichman E, Henderson D, Tamir O, Franz C, Song P, et al. (2013) Health care-associated infections: a meta-analysis of costs and financial impact on the US health care system. JAMA Intern Med 173: 2039-2046.

4. Merkow RP, Ju MH, Chung JW, Hall BL, Cohen ME, et al. (2015) Underlying reasons associated with hospital readmission following surgery in the United States. JAMA 313: 483-495.

5. Scott RD II (2009) The Direct Medical Costs of Healthcare-Associated Infections in US Hospitals and the Benefits of Prevention. Centers for Disease Control and Prevention, Atlanta, USA.
6. Anderson DJ, Podgorny K, Berríos-Torres SI, Bratzler DW, Dellinger $E P$, et al. (2014) Strategies to prevent surgical site infections in acute care hospitals: 2014 update. Infect Control Hosp Epidemiol 35: 605627.

7. Horan TC, Gaynes RP, Martone WJ, Jarvis WR, Emori TG (1992) CDC definitions of nosocomial surgical site infections, 1992: a modification of $C D C$ definitions of surgical wound infections. Infect Control Hosp Epidemiol 13: 606-608.

8. Mangram AJ, Horan TC, Pearson ML, Silver LC, Jarvis WR (1999) Guideline for Prevention of Surgical Site Infection, 1999. Centers for Disease Control and Prevention (CDC) Hospital Infection Control Practices Advisory Committee. Am J Infect Control 27: 97-132.

9. Howard DH, Scott RD II, Packard R, Jones D (2003) The global impact of antibiotic resistance. Clin Infect Dis 36: S4-S10.

10. Ban KA, Minei JP, Laronga C, Harbrecht BG, Jensen EH, et al. (2017) American College of Surgeons and Surgical Infection Society: Surgical Site Infection Guidelines, 2016 Update. J Am Coll Surg 224: 59-74.

11. Allegranzi B, Zayed B, Bischoff P, Kubilay NZ, de Jonge S, et al. (2016) New WHO recommendations on intraoperative and postoperative measures for surgical site infection prevention: an evidence-based global perspective. Lancet Infect Dis 16: e288-e303.

12. Berrios-Torres SI, Umscheid CA, Bratzler DW, Leas B, Stone EC, et al. (2017) Centers for Disease Control and Prevention guideline for the prevention of surgical site infection, 2017. JAMA Surg 152: 784-791.

13. Gupta K, Strymish J, Abi-Haidar Y, Williams SA, Itani KM (2011) Preoperative nasal methicillin-resistant Staphylococcus aureus status, surgical prophylaxis, and risk-adjusted postoperative outcomes in veterans. Infect Control Hosp Epidemiol 32: 791-796.

14. Allareddy V, Das A, Lee MK, Nalliah RP, Rampa S, et al. (2015) Prevalence, predictors, and outcomes of methicillin-resistant Staphylococcus aureus infections in patients undergoing major surgical procedures in the United States: a population-based study. Am J Surg 210: 59-67.

15. Kalra L, Camacho F, Whitener CJ, Du P, Miller M, et al. (2013) Risk of methicillin-resistant Staphylococcus aureus surgical site infection in patients with nasal MRSA colonization. Am J Infect Cont 41: 12531257.

16. Bull AL, Worth LJ, Richards MJ (2012) Impact of vancomycin surgical antibiotic prophylaxis on the development of methicillin-sensitive staphylococcus aureus surgical site infections: report from Australian Surveillance Data (VICNISS). Ann Surg 256: 1089-1092.

17. Abi-Haidar Y, Gupta K, Strymish J, Williams SA, Itani KM (2011) Factors associated with post-operative conversion to methicillinresistant Staphylococcus aureus positivity or infection in initially MRSA-negative patients. Surg Infect (Larchmt) 12: 435-442.

18. Toh JWT, Phan K, Hitos K, Pathma-Nathan N, El-Khoury T, et al. (2018) Association of mechanical bowel preparation and oral antibiotics before elective colorectal surgery with surgical site infection: a network meta-analysis. JAMA Netw Open 1: e183226.

19. Battersby CLF, Battersby NJ, Slade DAJ, Soop M, Walsh CJ (2019) Preoperative mechanical and oral antibiotic bowel preparation to reduce infectious complications of colorectal surgery-the need for updated guidelines. J Hosp Infect 101: 295-299.

20. Kiran RP, Murray AC, Chiuzan C, Estrada D, Forde K (2015) Combined preoperative mechanical bowel preparation with oral antibiotics significantly reduces surgical site infection, anastomotic leak, and ileus after colorectal surgery. Ann Surg 262: 416-425. 
21. Chen $M$, Song $X$, Chen LZ, Lin ZD, Zhang XL (2016) Comparing mechanical bowel preparation with both oral and systemic antibiotics versus mechanical bowel preparation and systemic antibiotics alone for the prevention of surgical site infection after elective colorectal surgery: a meta-analysis of randomized controlled clinical trials. Dis Colon Rectum 59: 70-78.

22. Nelson RL, Gladman E, Barbateskovic M (2014) Antimicrobial prophylaxis for colorectal surgery. Cochrane Database Syst Rev 5 : CD001181.

23. Morris MS, Graham LA, Chu DI, Cannon JA, Hawn MT (2015) Ora antibiotic bowel preparation significantly reduces surgical site infection rates and readmission rates in elective colorectal surgery. Ann Surg 261: 1034-1040.

24. Ata A, Lee J, Bestle SL, Desemone J, Stain SC (2010) Postoperative hyperglycemia and surgical site infection in general surgery patients. Arch Surg 145: 858-864.

25. Kao LS, Phatak UR (2013) Glycemic control and prevention of surgical site infection. Surg Infect (Larchmt) 14: 437-444.

26. Kotagal $M$, Symons RG, Hirsch IB, Umpierrez GE, Dellinger EP, et al. (2015) Perioperative hyperglycemia and risk of adverse events among patients with and without diabetes. Ann Surg 261: 97-103.

27. Hays RC, Mandell GL (1974) PO2, pH, and redox potential of experimental abscesses. Proc Soc Exp Biol Med 147: 29-30.
28. Allen DB, Maguire JJ, Mahdavian M, Wicke C, Marcocci L, et al. (1997) Wound hypoxia and acidosis limit neutrophil bacterial killing mechanisms. Arch Surg 132: 991-996.

29. Seamon MJ, Wobb J, Gaughan JP, Kulp H, Kamel I, et al. (2012) The effects of intraoperative hypothermia on surgical site infection: an analysis of 524 trauma laparotomies. Ann Surg 255: 789-795.

30. Silva JM, de Oliveira AM, Nogueira FA, Vianna PM, Pereira Filho MC, et al. (2013) The effect of excess fluid balance on the mortality rate of surgical patients: a multicenter prospective study. Crit Care 17: R288.

31. Nakamura T, Kashimura N, Noji T, Suzuki O, Ambo Y, et al. (2013) Triclosan-coated sutures reduce the incidence of wound infections and the costs after colorectal surgery: a randomized controlled trial. Surgery 153: 576-583.

32. Tanner J, Parkinson H (2006) Double gloving to reduce surgical crossinfection. Cochrane Database Syst Rev.

33. Cima R, Dankbar E, Lovely J, Pendlimari R, Aronhalt K, et al. (2013) Colorectal surgery surgical site infection reduction program: a National Surgical Quality Improvement Program-driven multidisciplinary single-institution experience. J Am Coll Surg 216: 23-33.

34. Wenzel RP (2010) Minimizing surgical-site infections. N Engl J Med 362: $75-77$. 